\title{
Probability of detection and positioning error of a hydro acoustic telemetry system in a fast-flowing river: Intrinsic and environmental determinants
}

\author{
Julien Bergéa ${ }^{a}{ }^{*}$, Hervé Capra ${ }^{a}$, Hervé Pella ${ }^{a}$, Tracey Steig ${ }^{b}$, Michaël Ovidio ${ }^{c}$, Elise Bultel ${ }^{a}$, \\ Nicolas Lamouroux ${ }^{\text {a }}$ \\ a IRSTEA, UR MALY, Laboratory Dynam, 3 bis Quai Chauveau - CP 220, F-69336 Lyon, France \\ ${ }^{\mathrm{b}}$ Hydroacoustic Technology Inc., 715 NE Northlake Way, Seattle, WA 98105, USA \\ c University of Liège, Biology of Behaviour Unit-Cefra, Laboratory of Fish Demography and Hydroecology (LDPH), 10 Chemin de la Justice, 4500 Tihange, Belgium
}

\section{A R T I C L E I N F O}

\section{Article history:}

Received 11 July 2011

Received in revised form 3 February 2012

Accepted 5 February 2012

\section{Keywords:}

Acoustic tags

Hydrophones configuration

Triangulation parameters

Aquatic fish behavior

\begin{abstract}
A B S T R A C T
In situ fixed acoustic telemetry methods make it possible to study simultaneously the detailed movements of individual fish and their relationship to the environment, but the properties of these methods is little known in harsh physical conditions. We examined the probability of tag detection by the system and the positioning error for detected tags of an existing telemetry system installed with 32 fixed hydrophones in a reach of the fast-flowing Rhône River in France. The reach was $1.8 \mathrm{~km}$ long and had heterogeneous thermal and hydraulic conditions described by a two-dimensional hydraulic model. We compared positions detected by the system with true positions estimated using a tachometer or a differential GPS, for various sets of experimental tag emissions. We analyzed how the probability of detection and the positioning error were affected by user-defined variables and three groups of environmental variables describing the configuration of the hydrophones around tag position, the physical environment at tag position and the reception quality. Tag emissions from the center channel had an average probability of detection (40-50\%) higher than emissions originating from positions close to the banks, and were positioned with smaller average errors $(3-5 \mathrm{~m})$. The probability of detection of emissions typically varied between near $0 \%$ and $80 \%$ with configuration variables (density of surrounding hydrophones and location of tag relative to the hydrophones) and also decreased in the presence of coarse substrate. The positioning error was mainly reduced when user-defined variables of the triangulation software were set by an expert user. Configuration variables also influenced the positioning error with weaker effects than those observed for detection probability.
\end{abstract}

(c) 2012 Elsevier B.V. All rights reserved.

\section{Introduction}

The sensitivity of fish and other freshwater organisms to changes in abiotic conditions of rivers has been reported in many studies with a particular emphasis on their ecological (e.g., behavioral, demographic, physiological) responses to modifications of hydrological or thermal regimes (Minns et al., 1996; Lukšiené et al., 2000; Vehanen et al., 2000; Ovidio et al., 2008; Craven et al., 2010; Olden and Naiman, 2010; Poff and Zimmerman, 2010). In particular, individual fish movements have often been related to short-term changes in discharge rate and temperature (Ovidio et al., 1998; Ovidio and Philippart, 2008). Behavioral studies in aquatic systems increasingly use biotelemetry (Lyons and Lucas, 2002; Cooke

\footnotetext{
* Corresponding author. Tel.: +334 7220 8732; fax: +334 78477875 .

E-mail addresses: julien.berge@irstea.fr (J. Bergé), herve.capra@irstea.fr (H. Capra), herve.pella@irstea.fr (H. Pella),tsteig@htisonar.com (T. Steig), M.Ovidio@ulg.ac.be (M. Ovidio), elise.bultel@gmail.com (E. Bultel), nicolas.lamouroux@irstea.fr (N. Lamouroux).
}

et al., 2004; Geeraerts et al., 2007; Ovidio et al., 2007) to record individual fish movements at different time steps, from seconds to multiple years (Lucas and Batley, 1996; Meyer and Hinrichs, 2000; Ehrenberg and Steig, 2003). The probability of detection and the positioning error are major characteristics of telemetry systems and have been improved in recent years. Low errors are essentially obtained with fixed acoustic telemetry systems that provide detailed information when sound transmitters (i.e. tags) are detected by acoustic hydrophones (Ehrenberg and Steig, 2003; Cooke et al., 2005). Compared to other systems, fixed systems enable the simultaneous detailed study of the movements of many individual fish. However, a better quantification of their properties is needed to find appropriate compromises between the probability of detection, the positioning error and the surface area covered by the system. For example, Clements et al. (2005) showed that the probability of detection of the VR2 system (Vemco Ltd, Canada) could vary between 0 and $100 \%$ in a stream reservoir and an estuary depending on the placement of the hydrophones and their mooring method. Cote et al. (1998), using the MAP_500 Lotek ${ }^{\circledR}$ system (Lotek Marine Technologies Inc., Ca) in the Bonavista Bay (Newfoundland, 
Canada), reported an average positioning error of $2 \mathrm{~m}$ or less inside the baseline of hydrophones used during a two months tracking of juvenile Atlantic cods (Gadus morhua, pulse rate of $5 \mathrm{~min}$ ). The 3-dimensionnal positioning error of the Vemco radio-acoustic positioning system was estimated in a South African bay (O'dor et al., 1998 ) to be about $1-2 \mathrm{~m}$ inside the hydrophones array and about 3-5 $\mathrm{m}$ when emissions were $100 \mathrm{~m}$ outside the array.

The probability of detection and the positioning error of telemetry systems potentially depend on a large number of intrinsic and environmental factors (Kell et al., 1994; Voegeli and Pincock, 1996). Intrinsic factors include the estimation of the speed of sound, the knowledge of exact hydrophone positions and the adjustment of the parameters of the positioning software (Juell and Westerberg, 1993; Cote et al., 1998; Wahlberg et al., 2001; Ehrenberg and Steig, 2002). Among environmental factors, weak spatial configurations of hydrophones relative to the tag location (long distances, narrow viewing angles) have been identified as influencing the probability of detection and the positioning error (Baras and Lagardère, 1995; Smith et al., 1998; Ehrenberg and Steig, 2002; Niezgoda et al., 2002; Simpfendorfer et al., 2002; Heupel et al., 2006; Espinoza et al., 2011). In addition, the probability of detection and the positioning error likely decrease in heterogeneous substrate, hydraulic and thermal conditions that can favor sound refraction, ambient noise and variations in speed of sound (Voegeli and Pincock, 1996; Trevorrow, 1998; Ehrenberg and Steig, 2002). Quantifying the combined influence of intrinsic and environmental characteristics of the study site on the system properties can improve further study designs. It is particularly needed for telemetric studies made in fastflowing rivers, whose heterogeneous physical characteristics may complicate tag detection and positioning.

In summer 2009, an acoustic fixed telemetry system $\left(\mathrm{HTI}^{\circledR}\right)$ was installed in a physically heterogeneous reach of the fast-flowing Rhône River in France to analyze the behavioral response of fish to variations in discharge rate (due to hydropeaking) and water temperature (warm water is discharged in the reach by a nuclear power plant). In this paper, we describe how we used this installation (1) to quantify the probability of detection and the positioning error of the telemetry system in a fast-flowing heterogeneous river, (2) to infer which intrinsic and environmental variables influence the detection and the position errors, and (3) to discuss methods for optimizing installations in future studies. For this purpose, we simultaneously estimated tag positions in the river using the $\mathrm{HTI}^{\circledR}$ system and using an independent "reference" differential GPS or tachometer. We studied how the probability of detection and the positioning error were affected by the user-defined variables in the telemetry system (intrinsic variables), and various environmental variables associated with tag positions.

\section{Materials and methods}

\subsection{Study site}

The Rhône river has a drainage basin area of $98,556 \mathrm{~km}^{2}$ and a mean annual discharge of $1720 \mathrm{~m}^{3} \mathrm{~s}^{-1}$ at its mouth (Olivier et al., 2009). Our study reach was $1.8 \mathrm{~km}$ long and $140 \mathrm{~m}$ wide (at mean discharge) and was situated at Bugey $\left(45^{\circ} 47^{\prime} \mathrm{N} ; 5^{\circ} 16^{\prime} \mathrm{E}\right)$, upstream from the confluence of the Ain River and the town of Lyon, in the longest Rhône segment without discharge derivation (Fig. 1). The Rhône at Bugey has a nival hydrological regime (i.e. under the influence of snowmelt) characterized by a mean monthly discharge ranging from $387 \mathrm{~m}^{3} \mathrm{~s}^{-1}$ in September to $567 \mathrm{~m}^{3} \mathrm{~s}^{-1}$ in June. Mean annual discharge is $473 \mathrm{~m}^{3} \mathrm{~s}^{-1}$, and the mean daily discharge ranges from $197 \mathrm{~m}^{3} \mathrm{~s}^{-1}$ (exceeded 95\% of the time) to $933 \mathrm{~m}^{3} \mathrm{~s}^{-1}$ (exceeded 5\% of the time). A high discharge variability (daily changes up to $700 \mathrm{~m}^{3} \mathrm{~s}^{-1}$, Olivier et al., 2009) is

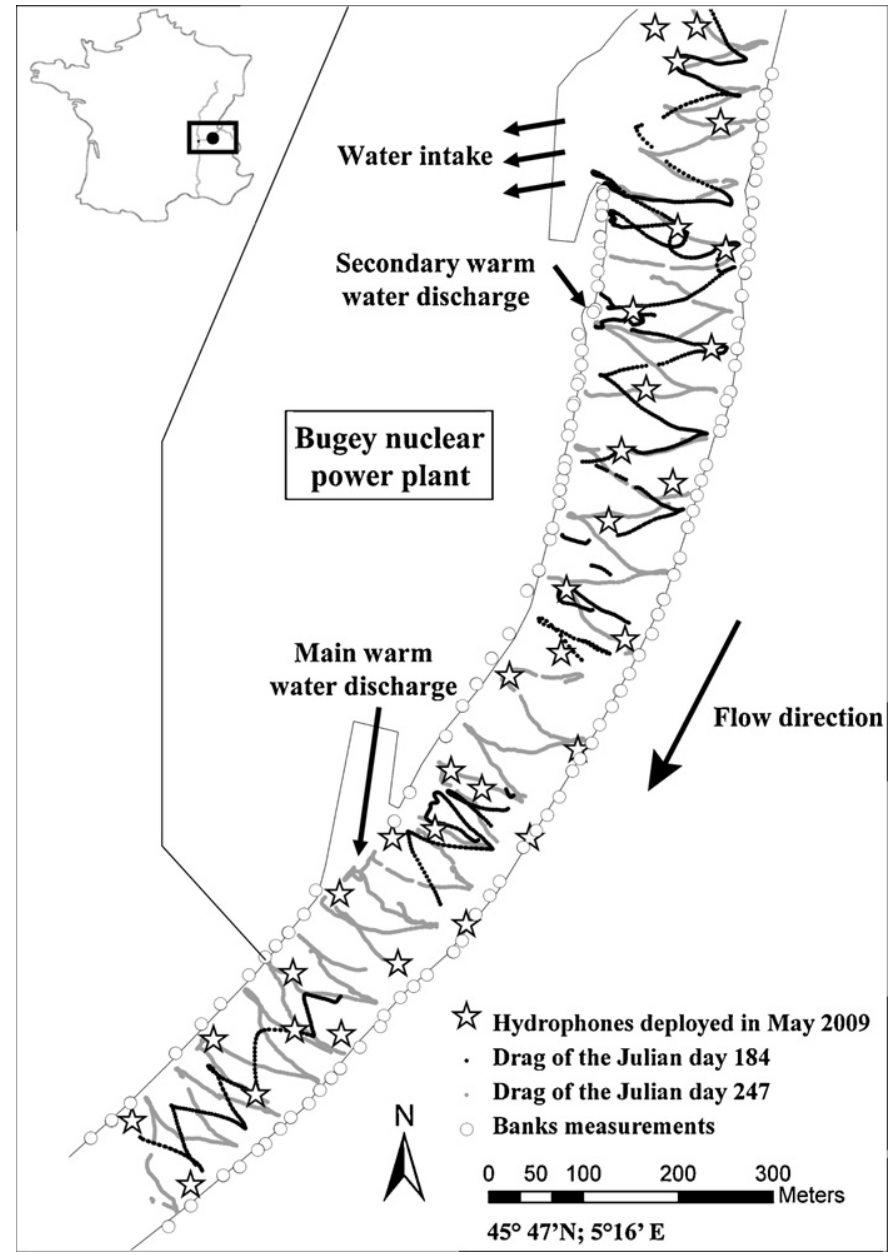

Fig. 1. Location of the Bugey site on the Rhône River in France. Hydrophone positions and survey points.

generally observed during the week due to hydropeaking at upstream dams, and discharge is generally lower and more stable during week-ends. At mean discharge, point depth-averaged velocity reaches $1.8 \mathrm{~m} \mathrm{~s}^{-1}$ and point depth reaches $8 \mathrm{~m}$. The substrate composition was mapped using a combination of visual observations from a boat and high resolution aerial photographs. Substrate size was assigned to one of five ordinal classes and consisted of pebbles (36.0\% of the surface area), gravel $(26.4 \%)$, stones (14.4\%), blocks (13.9\%) and sand (8.2\%). The daily water temperature upstream from the study reach ranged in 2009 from $2.8^{\circ} \mathrm{C}$ to $23.6^{\circ} \mathrm{C}$ (Roger et al., 2010). A nuclear power plant (Bugey Power Plant), located on the west bank of the study reach, extracts $100 \mathrm{~m}^{3} \mathrm{~s}^{-1}$ to cool reactors and discharges warmer water (between 8 and $10^{\circ} \mathrm{C}$ warmer) at two different places (Fig. 1), creating a strong transversal thermal heterogeneity. No vertical thermal stratification was observed in the reach (Capra et al., 2008). Downstream from the nuclear power plant, the warmed water cools down by around $1{ }^{\circ} \mathrm{C}$ per kilometer, and diffuses from the west bank to the whole channel $10 \mathrm{~km}$ downstream (Capra et al., 2008). Water turbidity recorded in 2009 ranged between $9.5 \mathrm{mg} \mathrm{l}^{-1}$ in February and $81 \mathrm{mg} \mathrm{l}^{-1}$ in November (Roger et al., 2010).

A two-dimensional hydraulic model of the reach was developed using (1) a digital elevation model based on extensive field measurements of topography and bathymetry (an average of four measuring points per $\mathrm{m}^{2}$, Pella et al., 2007), (2) water level discharge relationship records, and (3) velocity measurements at different discharge rates (Capra et al., 2011). The hydraulic model 
was calibrated and validated for a discharge rate between 150 and $850 \mathrm{~m}^{3} \mathrm{~s}^{-1}$. Differences between simulated and measured water levels were found to be around $1 \mathrm{~cm}$, and a comparison of measured and simulated velocities did not show errors exceeding $0.1 \mathrm{~m} \mathrm{~s}^{-1}$ across the study site (Capra et al., 2011).

\subsection{Telemetry system principles and deployment}

We used an $\mathrm{HTI}^{\circledR}$ automatic acoustic telemetry system that included a set of pre-positioned hydrophones used to detect ultrasounds emitted by acoustic tags of various sizes, programmed with a frequency of $307 \mathrm{KHz}$ (Ehrenberg and Steig, 2003). Each hydrophone was cabled to a receiver unit (the Acoustic Tag Receiver, model 290) that recorded acoustic signals and stored them on a computer. The Acoustic Tag Receiver was synchronized with UTC time (Universal Time Coordinated) thanks to an internal GPS, and its digital signal processor had a precision of $12 \mathrm{KHz}$. We used Model 795G tags (transmit power level: $155 \mathrm{~dB}$ relative to $1 \mu \mathrm{Pa}$ at $1 \mathrm{~m}$; length: $25 \mathrm{~mm}$; diameter: $11 \mathrm{~mm}$; weight: $3.1 \mathrm{~g}$ ). The average lifetime of tags was about 50 days in our experimental conditions (according to the manufacturer). Tag signals were series of pulses ( $1 \mathrm{~ms}$ long in our experiment) sent with different periods $P$ ( $P$ varied around $3 \mathrm{~s}$ in our experiment) that were used to identify and track individual tags. A secondary signal, called "subcode", which was a replication of the first signal, was used to improve tag signal reception and the identification of each tag in noisy environments. The subcode was usually not used for positioning tags, but sometimes it could be considered by the system as another principal signal. In such a case, two positions were estimated with close emission times. Such "duplicate" positions were identified and filtered. In our experiment, we positioned tags in two dimensions (2D). A three dimensional (3D) positioning of tags was not feasible because the study site had too little vertical separation in the hydrophone array to resolve tag depth. For our 2D analysis, the acoustic tag signal must be received by at least three hydrophones. Only three hydrophones were selected by the system to position a given tag and are called thereafter the "listening trio". During a post treatment stage, arrival times of pulses received by hydrophones were used to estimate the coordinates of tags at signal emission and the emission time. The post treatment of the acoustic signals (filtering and triangulation) was made using successively two $\mathrm{HTI}^{\circledR}$ proprietary softwares (see http://www.htisonar.com/).

A total of 32 hydrophones were installed in May 2009 (Fig. 1) and $16 \mathrm{~km}$ of weighted acoustic cables were used to connect them to the Acoustic Tag Receiver. The connection of acoustic cables to the hydrophones was made by a diver. Each hydrophone was mounted on a concrete block of $300 \mathrm{~kg}$ (Fig. 2) and deposited on the river bed using a boat; an operation that was sometimes difficult due to high current velocities. The hydrophone was positioned about $10 \mathrm{~cm}$ above the block, and the block could constitute an acoustic shadow for signals emitted from the bottom within an area of about $10 \mathrm{~m}^{2}$ around the block. Hydrophone positions were predefined using the digital elevation model so that most emission points could be a priori heard by more than three hydrophones, as recommended by Kell et al. (1994) or Voegeli and Pincock (1996), while taking into account that the theoretical detection (hearing) range of hydrophones was $300 \mathrm{~m}$ (according to the manufacturer). We released hydrophones at pre-defined positions using a dGPS (Leica ${ }^{\circledR} 1200$ ) and a real time track process on a computer taken on board. Pre-defined coordinates were stored in Matrix M1. Because of local hydraulic or substrate constraints, seven hydrophones were positioned a few meters away from their pre-defined position. Their theoretical coordinates in M1 were replaced by coordinates measured in the field with a tachometer (Leica ${ }^{\circledR} 800$ ). At the end of the study (on September 18, 2009), the coordinates of the hydrophones

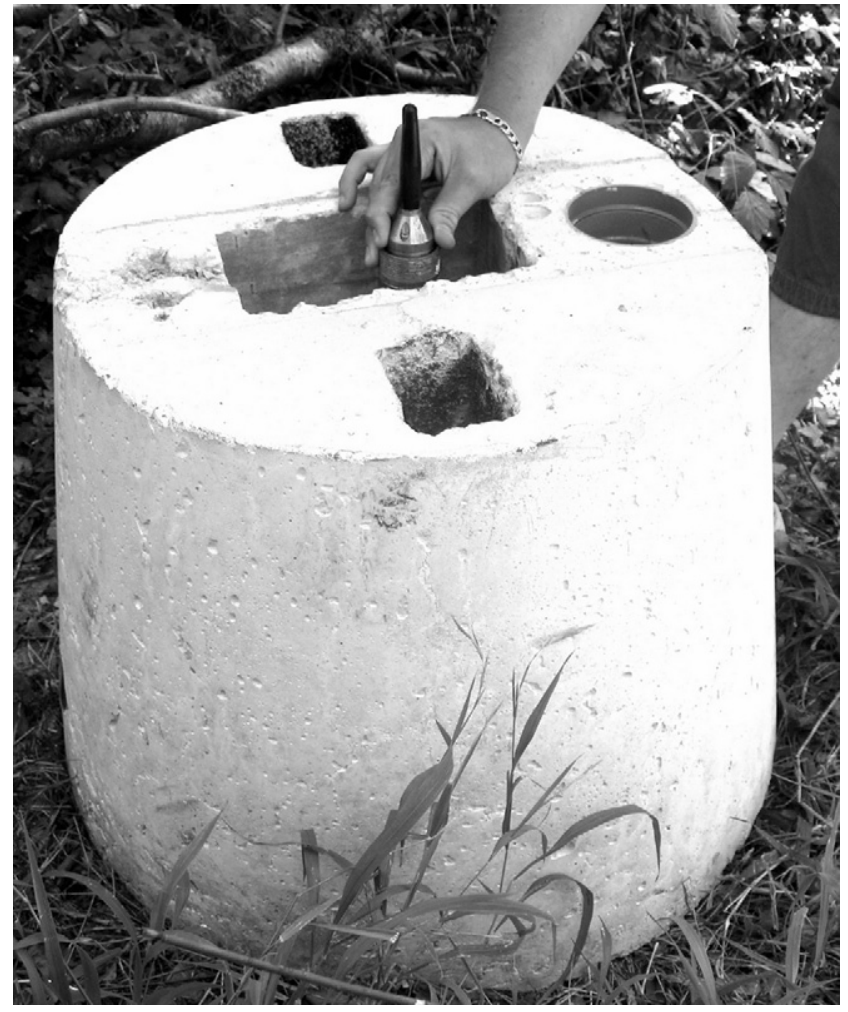

Fig. 2. Concrete block of $300 \mathrm{~kg}$ and its hydrophone.

were again measured with a dGPS (Leica ${ }^{\circledR} 1200$ ) and were stored in Matrix M2.

\subsection{Data used for estimating the probability of detection and positioning errors}

Two different sets of data were collected, one by dragging tags over the whole study site from a boat (drags data), and the other by holding tags at fixed locations along the banks (banks data). In both cases, the objective was to compare tag positions estimated by the $\mathrm{HTI}^{\circledR}$ system with reference positions measured by dGPS or tachometer. We estimated the detection probability of tags by the proportion of known emissions actually positioned by the HTI ${ }^{\circledR}$ system, and the positioning error of detected tags by the Euclidian distance between $\mathrm{HTI}^{\circledR}$ estimated position and the reference positions. The dGPS and tachometer systems used have themselves a centimetric positioning error (given in Takac and Walford, 2006, for the dGPS and by the manufacturer for the tachometer) and we assumed that they provided true positions. Because the errors of the dGPS and tachometer and the errors of the $\mathrm{HTI}^{\circledR}$ system can be assumed independent, our estimation of positioning error is conservative.

Drags data were collected with the dGPS during two surveys of the whole site by boat (Fig. 1), following zigzag trajectories at reduced relative velocity (less than $1 \mathrm{~ms}^{-1}$ ) to limit potential effects of the boat movement on the probability of detection (Melnychuk and Christensen, 2009). Characteristics of the two drag surveys are presented in Table 1 . A NKE ${ }^{\circledR}$ SP2 T sonde $\left( \pm 0.05^{\circ} \mathrm{C}\right)$ recorded water temperature every second. During drags, we used four tags with emission periods $P$ equal to $3051,3079,3121$ and $3247 \mathrm{~ms}$, and subcodes emitted $225 \mathrm{~ms}$ after the principle signal. Tags were attached to the base of a pole supporting the antenna of the dGPS: two tags were submerged $50 \mathrm{~cm}$ below the surface and two tags were submerged at $1 \mathrm{~m}$. UTC time was assigned to each boat's position recorded by the dGPS (frequency: $1 \mathrm{~Hz}$ ). The data corresponding to the four tags were pooled for the analyses. 
Table 1

Characteristics of drags and banks data. Water temperatures are daily averages measured at fixed points situated upstream from the site and at power plant warm discharges.

\begin{tabular}{|c|c|c|c|c|}
\hline \multirow[t]{3}{*}{ Data set characteristics } & \multicolumn{2}{|c|}{ Drags data } & \multicolumn{2}{|c|}{ Banks data } \\
\hline & July & September & June & June \\
\hline & $3 r d$ & 4 th & 24 th & 25 th \\
\hline Recording time (min) & 101.0 & 132.0 & 26.0 & 33.5 \\
\hline Daily discharge $\left(\mathrm{m} \mathrm{s}^{-1}\right)$ & 546.0 & 525.0 & 519.0 & 522.0 \\
\hline \multicolumn{5}{|l|}{ Water temperature $\left({ }^{\circ} \mathrm{C}\right)$} \\
\hline Cold zone & 22.1 & 21.1 & 17.3 & 18.4 \\
\hline Main power plant discharge & 29.1 & 23.3 & 24.8 & 26.1 \\
\hline Secondary power plant discharge & 31.5 & 30.1 & 26.0 & 27.4 \\
\hline
\end{tabular}

The banks data set was less extensive and targeted shallower habitats where the boat could not navigate and where the dGPS could not work due to the presence of trees. We collected these data over two days (June $24-25,2009$ ) with a tachometer at 114 fixed locations chosen along both banks of the study site (Fig. 1). Characteristics of banks measurements are presented in Table 1. One tag (with $\mathrm{P}$ equal to 3121 or $3205 \mathrm{~ms}$ and subcode set up at $225 \mathrm{~ms}$ ) was attached to the tachometer tip and we submerged the tag during a $15 \mathrm{~s}$ sequence just under the surface and just above the bed (one sequence each) at each fixed location. Each fixed location was measured for each sequence of $15 \mathrm{~s}$ and a UTC time was recorded for each tachometer measurement.

\subsection{Estimating true positions at emission times}

All periods of times with dGPS gaps (absence of data) longer than $5 \mathrm{~s}$ were removed from all analyses to reduce dGPS interpolation errors. Before analyzing detection probability and positioning errors, we estimated true positions at emission times (UTC) using the dGPS and tachometer data, for all emissions, detected or not, by the $\mathrm{HTI}^{\circledR}$ system. Concerning positions detected by the $\mathrm{HTI}^{\circledR}$ system, the dGPS positions of drag data corresponding to the emission times $\left(t_{i}\right)$ were interpolated from the raw dGPS data (gaps up to $5 \mathrm{~s}$ ) using cubic spline functions that smoothed the $x$ and $y$ dGPS coordinates (Fritsch and Carlson, 1980; R Development Core Team, 2010). Concerning positions undetected by the $\mathrm{HTI}^{\circledR}$ system, virtual emission times were estimated. Specifically, for each tag of emission period $\mathrm{P}$ and for each detected emission time by the $\mathrm{HTI}^{\circledR}$ system $\left(t_{i}\right)$, if no position was estimated at $t_{i}+P( \pm 0.5 \mathrm{~s}$ of tolerance), we considered that an emission was undetected. In this case, we considered that $t_{i}+P$ was a virtual emission time. The virtual coordinates of this virtual emission time were interpolated from the dGPS data as described above and the position obtained was called a "virtual position". Several $(k)$ consecutive virtual emission times could be identified using the same principle, and these virtual emission times were set as $t_{i}+P, t_{i}+2 P \cdots t_{i}+k P$. Similarly, virtual emission times were identified between the start of the experiment and the first detection.

\subsection{Intrinsic and environmental variables relationship with the probability of detection and positioning errors}

We organized explanatory variables into one group of userdefined variables, and three groups of environmental variables: (1) the configuration of hydrophones surrounding tag positions (detected and virtual), (2) the physical characteristics at tag positions (detected and virtual), and (3) indicators of reception conditions (detected positions only). All variables were calculated similarly for drags and banks data.
User-defined variables can affect both detection probability and positioning error. These variables include: (1) the speed of sound $(\mathrm{SpS})$, which determined how time was translated into distances in the positioning algorithm, (2) the hydrophone coordinates listed in the positions Matrix (M) and (3) a series of 19 Post-Treatment parameters (PT, detailed in Supplementary file S1). We analyzed the effects of SpS by using two SpS values: a first value of $1482 \mathrm{~m} \mathrm{~s}^{-1}$ corresponding to the SpS recorded in pure water at a temperature of $20^{\circ} \mathrm{C}$, and a second value of $1509 \mathrm{~m} \mathrm{~s}^{-1}$ corresponding to a SpS at $30^{\circ} \mathrm{C}$ (Del Grosso and Mader, 1972). These values cover the temperature variations observed in our site during the experiment (Table 1). Hereafter, we refer to $\mathrm{SpS}$ values using their equivalent temperature $\left(20^{\circ} \mathrm{C}\right.$ and $\left.30^{\circ} \mathrm{C}\right)$. We analyzed the effects of $\mathrm{M}$ using the matrices M1 and M2 that corresponded respectively to the hydrophone coordinates at the beginning and at the end of the experiment. PT parameters values were closely dependant on the user and on his experience of system operation. The influence of PT values was tested by using two independent sets of parameters defined by two persons using the same field data: $13 \mathrm{~h}$ of survey of 17 tagged fish tracked on the 18 August 2009 throughout the site. The first set of PT values were defined by J. Bergé (PT-JB) and was based on an analysis of the influence of each parameter on the number of positioned points and the spatial consistency of these positions. The second set of PT values were defined by HTI ${ }^{\circledR}$ engineers (PT-HTI) using similar criteria but with greater acoustical experience, and experience with the acoustic equipment and positioning software. Overall, we used a total of eight user defined combinations ( $2 \mathrm{SpS} \times 2 \mathrm{M} \times 2 \mathrm{PT}$, named $\mathrm{C} 1-\mathrm{C} 8$ and detailed in Table 2) to infer the influence of user-defined variables.

Among environmental variables (Table 3), the first group (configuration of hydrophones) included two variables. First, the viewing angle (C-VA, "C" for configuration) was defined as the angle needed, from the tag position, to view the polygon formed by the surrounding hydrophones (i.e. those located in a radius of $300 \mathrm{~m}$, equal to the theoretical range of detection of hydrophone). When the tag was present inside the polygon, C-VA was equal to $360^{\circ}$. The second variable was the number of hydrophones ( $\left.\mathrm{C}-\mathrm{NH}\right)$ situated within a radius of $300 \mathrm{~m}$. The second group of environmental variables (physical characteristics) described the physical environment at tag positions (detected or virtual). It included: the depth-averaged current velocity (P-CV, "P" for physical), the size of the dominant substrate in the water column relative to water depth (relative roughness, $\mathrm{P}-\mathrm{RR}$ ), the depth (P-Dp) and the water temperature (P-WT). P-CV and P-Dp were obtained from the hydraulic model, and P-WT was recorded by the NKE recorder (drags data) and by thermometers installed along the banks (temperatures were interpolated using spline functions for both sampling methods). The third group (indicators of reception conditions) included four variables potentially explaining positioning errors, and concerned detected positions only. The first variable was the maximal distance between the tag location and the hydrophones of the listening trio (I-MD, "I" for indicator). The second variable was the maximal angle of the triangle formed by the listening trio (I-MAT, in degrees) and illustrated the form of this triangle (flat triangle when I-MAT approaches $180^{\circ}$ ). The third variable was the viewing angle needed, from the tag position, to view the triangle formed by listening trio (I-VA). The last variable was the amount of ambient noise, i.e. sounds produced naturally in the environment recorded by the listening trio (Voegeli and Pincock, 1996). A Noise Ratio (INR, equivalent to the signal-to-noise ratio index used by Cote et al., 1998) was calculated for each hydrophone of the listening trio, by dividing (1) the highest amplitude of the received signal (echo) in samples recorded by the hydrophone, by (2) the average noise level recorded over $1 \mathrm{~s}$ prior to the signal reception. The minimum I-NR (maximum noise) of the listening trio was retained as explanatory variable. 
Table 2

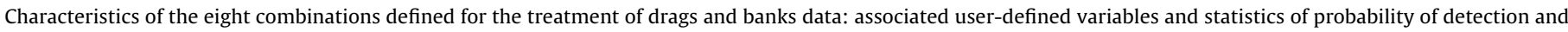
positioning error. The mean positioning errors are given with their standard errors.

\begin{tabular}{|c|c|c|c|c|c|c|c|c|c|}
\hline \multirow[t]{2}{*}{ Combination characteristics } & \multirow[t]{2}{*}{ Methods } & \multicolumn{8}{|c|}{ Combinations } \\
\hline & & $\mathrm{C} 1$ & $\mathrm{C} 2$ & $\mathrm{C} 3$ & $\mathrm{C} 4$ & C5 & C6 & $\mathrm{C} 7$ & $\mathrm{C} 8$ \\
\hline \multicolumn{10}{|l|}{ User-defined variables } \\
\hline $\mathrm{SpS}\left({ }^{\circ} \mathrm{C}\right)$ & & 20 & 30 & 20 & 30 & 20 & 30 & 20 & 30 \\
\hline $\mathrm{M}$ & & M1 & M1 & M1 & M1 & M2 & M2 & M2 & M2 \\
\hline PT & & HTI & HTI & JB & JB & HTI & HTI & JB & JB \\
\hline \multicolumn{10}{|l|}{ Accuracy statistics } \\
\hline \multirow[t]{2}{*}{ Probability of detection (\%) } & Drag & 41.9 & 41.6 & 34.6 & 35.5 & 47.2 & 43.9 & 42.1 & 38.9 \\
\hline & Bank & 16.7 & 14.6 & 8.3 & 8.8 & 17.7 & 16.0 & 9.6 & 8.9 \\
\hline \multirow[t]{2}{*}{ Mean positioning error (m) } & Drag & $5.7 \pm 0.05$ & $5.5 \pm 0.08$ & $10.7 \pm 0.16$ & $9.9 \pm 0.16$ & $4.5 \pm 0.06$ & $3.6 \pm 0.05$ & $10.1 \pm 0.14$ & $9.3 \pm 0.14$ \\
\hline & Bank & $8.3 \pm 0.62$ & $10.7 \pm 0.59$ & $11.5 \pm 1.24$ & $22.3 \pm 3.68$ & $8.2 \pm 0.70$ & $9.5 \pm 0.79$ & $7.7 \pm 0.80$ & $10.5 \pm 1.09$ \\
\hline
\end{tabular}

\subsection{Data analysis}

We analyzed the data in two steps. First, in a "within combination analysis", we analyzed how environmental variables influenced the probability of detection and the positioning error within each combination (C1-C8). For this purpose, we produced plots of the average probability of detection and the average positioning error for ordinal categories of each environmental variable. We also produced smoothed maps of the probability of detection and the positioning error over the entire study site to check for spatial patterns related to the environment. The inter-correlation between environmental variables was checked using scatter plots and by computing Spearman rank correlation $\rho$ for each pair of variables.

In a second step we performed a "between combination analysis", i.e. we analyzed the average detection probability and the average positioning error associated with the eight combinations of user-defined variables (C1-C8), for drags and banks data. To better inform future users of the telemetry system, the effect of the 19 PT parameters was further detailed using a sensitivity analysis. Once the most accurate PT combination identified (PT-JB or PT-HTI), each parameter was modified in turn and was given two to four values within the usual range covered in practical applications. The set of values included the extreme values of the usual range of the parameter, and the values chosen in PT-JB and PT-HTI. We quantified the changes in probability of detection and positioning error among the different parameter values.

\section{Results}

\subsection{General functionality of the system}

Due to flow variability or scouring, four hydrophones did not work at all during the whole experiment; they included the first three hydrophones located in the upstream part of the study site (Fig. 1). Seven additional hydrophones did not work during the first drag, five during the second drag and two during bank measurements. For each data set, only functioning hydrophones were considered for calculating $\mathrm{C}-\mathrm{NH}$ and $\mathrm{C}-\mathrm{VA}$. Six hydrophone positions could not be measured in September due to harsh hydraulic conditions, including the three hydrophones of the upstream part of the study site which never worked. For the three other hydrophones, we did not modify the coordinates of the hydrophones between matrices M1 and M2. The comparison of M1 and M2 indicated that twelve hydrophones had moved: 10 moved less than $6 \mathrm{~m}$ and two moved between 6 and $10 \mathrm{~m}$. Concerning the positions estimated by the $\mathrm{HTI}^{\circledR}$ system (detected positions), approximately $40 \%$ of them presented duplicates which were not used for the analyses. In addition, $13.5 \%$ of detected positions corresponded to positions extrapolated by the positioning software, i.e. that were derived using temporal extrapolations of reception signals at some hydrophones. These extrapolated positions can be identified and removed from the database. However, we included these positions in our analyses because they were dependent on the choice of user-defined variables and were an integral part of the positioning results. Finally, a total of 12,152 tag emissions (drag

Table 3

Environmental variables: notations and definitions.

\begin{tabular}{|c|c|c|c|}
\hline Environmental Variable & Symbol & Unit & Description \\
\hline \multicolumn{4}{|l|}{ Configuration variables } \\
\hline Viewing angle & C-VA & $\circ$ & $\begin{array}{l}\text { The angle needed, from the tag position, to view the polygon formed by the } \\
\text { surrounding hydrophones }\end{array}$ \\
\hline Density of hydrophones & $\mathrm{C}-\mathrm{NH}$ & & $\begin{array}{l}\text { Number of hydrophones situated within a radius of } 300 \mathrm{~m} \text { around the tag } \\
\text { location }\end{array}$ \\
\hline \multicolumn{4}{|l|}{ Physical characteristics } \\
\hline Current velocity & $\mathrm{P}-\mathrm{CV}$ & $\mathrm{ms} \mathrm{s}^{-1}$ & Depth-averaged velocity at tag position \\
\hline Relative roughness & P-RR & $\%$ & Substrate size divided by depth at tag position \\
\hline Depth & P-Dp & $\mathrm{m}$ & Water depth at tag position \\
\hline Water temperature & P-WT & ${ }^{\circ} \mathrm{C}$ & Water temperature at tag position \\
\hline \multicolumn{4}{|l|}{ Indicators of reception conditions } \\
\hline Maximal distance & I-MD & $\mathrm{m}$ & $\begin{array}{l}\text { Maximal distance between the tag location and the hydrophones of the } \\
\text { listening trio }\end{array}$ \\
\hline Maximal angle of the triangle & I-MAT & $\circ$ & Maximal angle of the triangle formed by the listening trio \\
\hline Viewing angle & I-VA & $\circ$ & $\begin{array}{l}\text { The angle needed, from the tag position, to view the triangle formed by } \\
\text { listening trio }\end{array}$ \\
\hline Noise ratio & I-NR & & $\begin{array}{l}\text { Ratio of the highest amplitude of the received signal a hydrophone, by the } \\
\text { average noise level recorded over } 1 \mathrm{~s} \text { prior to the signal reception }\end{array}$ \\
\hline
\end{tabular}



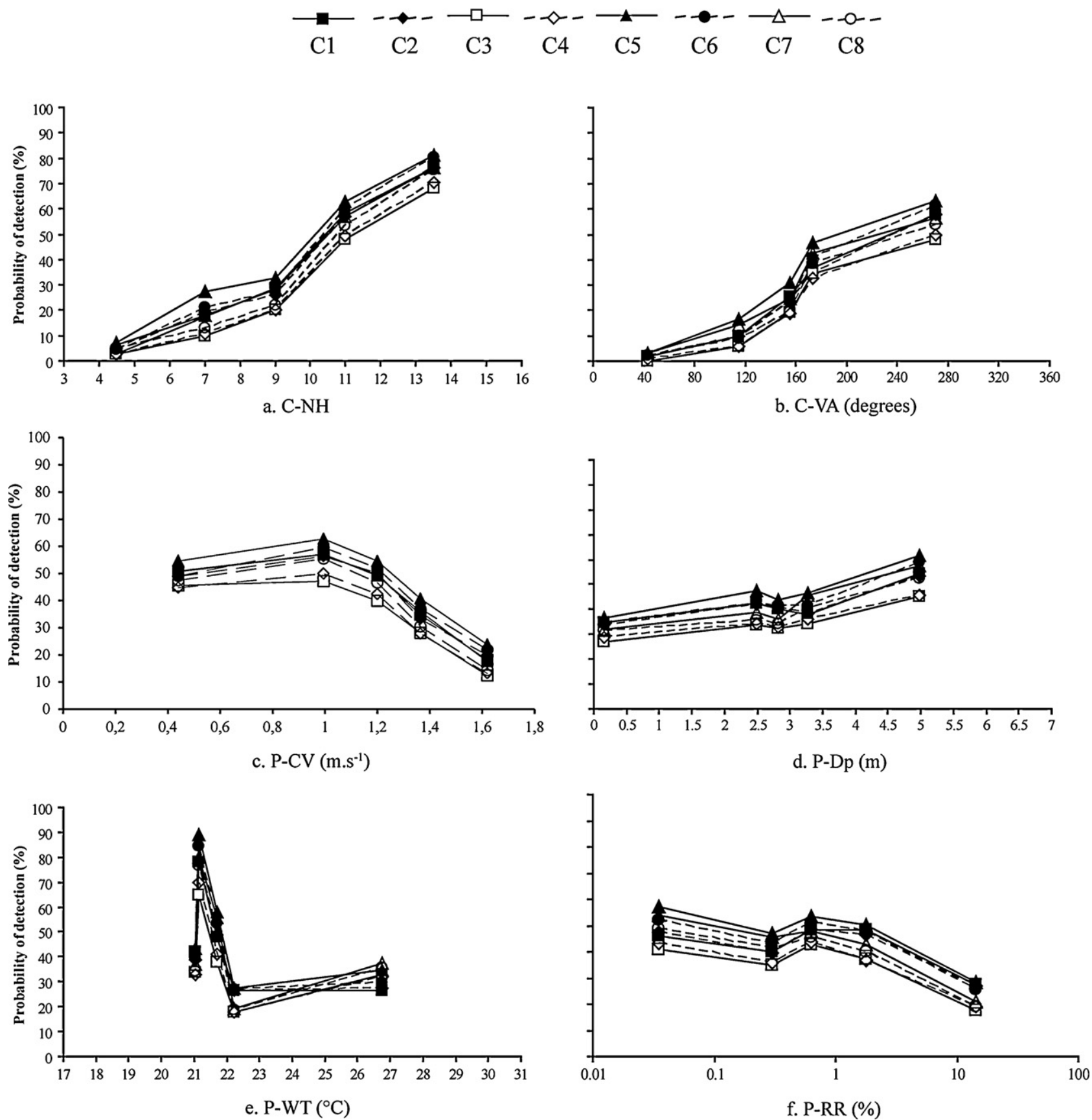

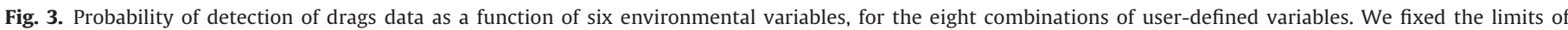

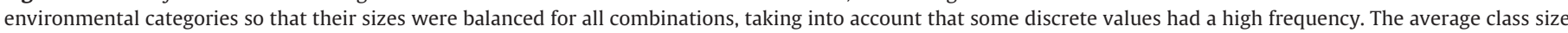
across combinations and classes was 2429 (standard deviation=1051). Note that the $x$-axis was log-transformed for the P-RR variable.

data) and 1140 tag emissions (banks data) were considered in our analyses.

\subsection{Environmental effects on detection probability within combinations}

A number of environmental variables influenced the probability of detection consistently within the eight combinations of user-defined variables (Fig. 3 and Fig. 4). Detection probability was mainly influenced by configuration variables. Detection probability increased with $\mathrm{C}-\mathrm{NH}$ within all combinations, for banks and drags data: from $<10 \%$ for $\mathrm{C}-\mathrm{NH}<6$ to about $70 \%$ for $\mathrm{C}-\mathrm{NH}>12$ for drags data (Fig. 3a) and from $0 \%$ for C-NH $<6$ to about $30 \%$ for C-NH $>14$ for banks data (Fig. 4a). The detection probability also increased with
C-VA from less than 5\% (drags and banks, Fig. 3b and Fig. 4b) to about $55 \%$ for drags (Fig. 3b) and 20\% for banks (Fig. 4b). Physical variables also influenced the probability of detection, since very high P-CV $\left(>1.44 \mathrm{~m} \mathrm{~s}^{-1}\right)$ reduced the probability of detection from around $50 \%$ to $20 \%$ for drags (Fig. 3c), whereas low P-CV $\left(<0.52 \mathrm{~m} \mathrm{~s}^{-1}\right)$ reduced the probability of detection from around $30 \%$ to less than $10 \%$ for banks (Fig. $4 \mathrm{c}$ ). Low P-Dp $(<2.31 \mathrm{~m})$ were also associated with reduced detection probabilities, for drags and banks (Fig. $3 \mathrm{~d}$ and Fig. 4d). High P-RR values ( $>2.8 \%$, Fig. 3f) could reduce about twofold the probability of detection for drags, and to a lesser extent for banks (Fig. 4f). An intermediate temperature category was also associated with higher detection probabilities, but this temperature differed for drags $\left(21.1^{\circ} \mathrm{C}\right.$, Fig. 3e) and banks $\left(17.44^{\circ} \mathrm{C}\right.$, Fig. $\left.4 \mathrm{e}\right)$. Banks data generally covered shallower and slower-flowing 


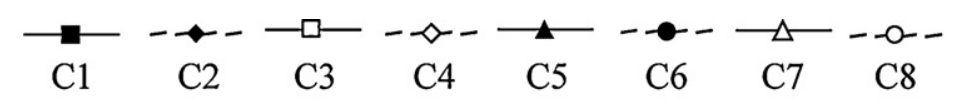

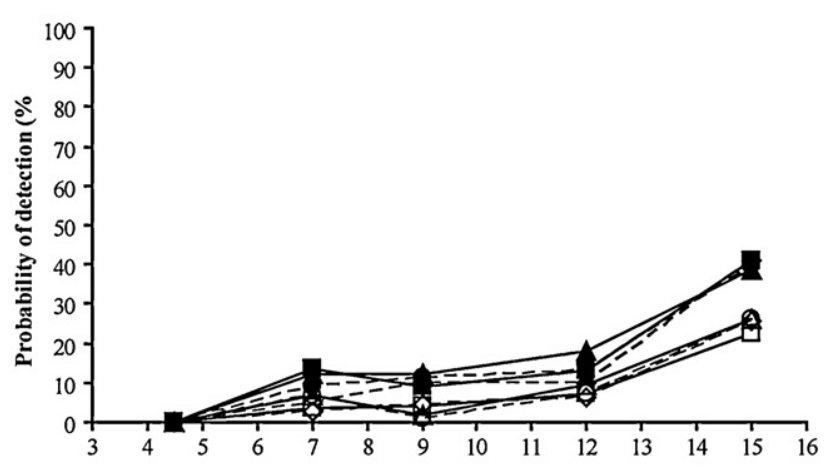

a. $\mathrm{C}-\mathrm{NH}$
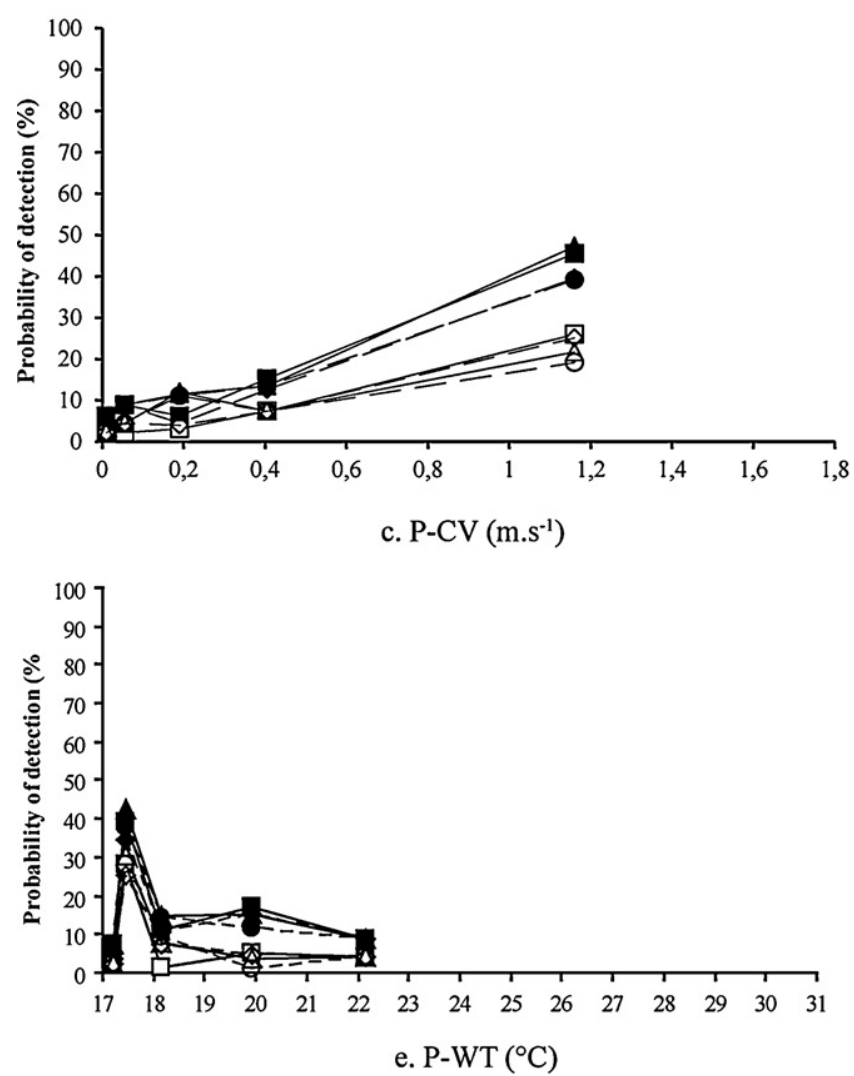
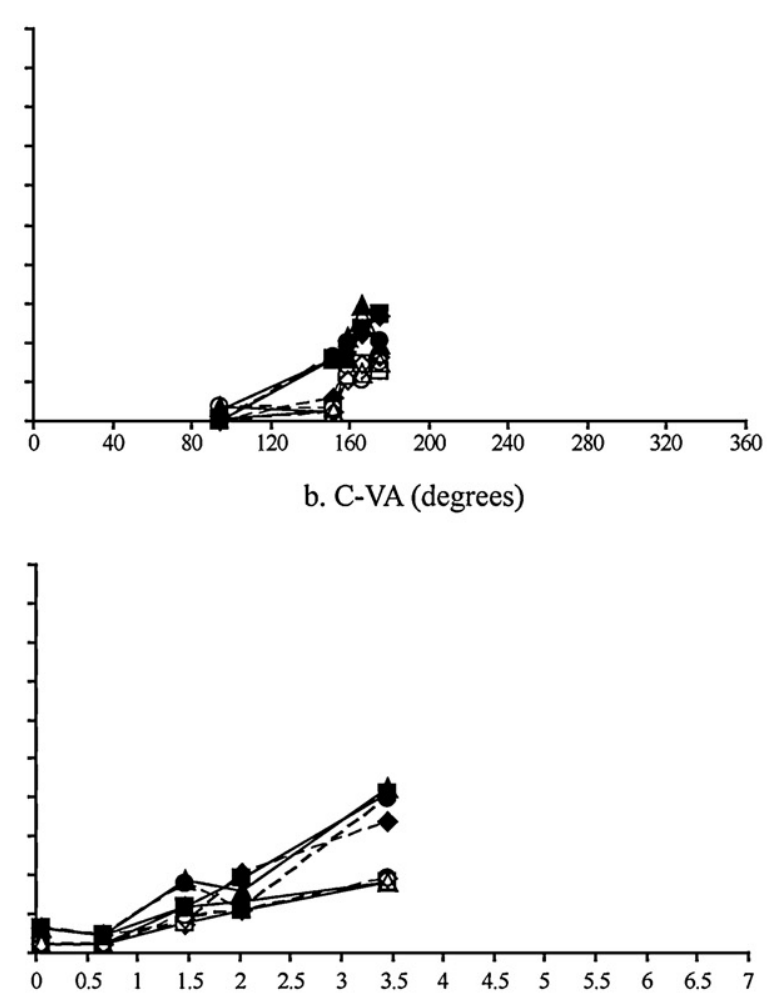

d. P-Dp (m)

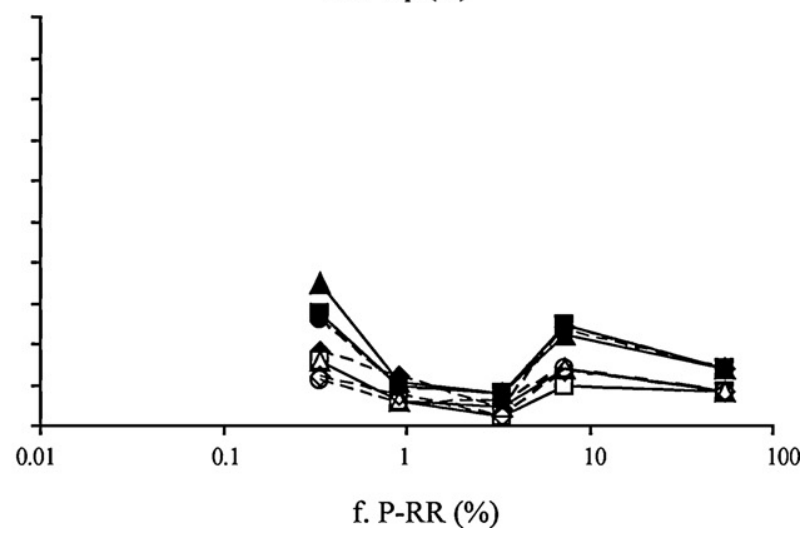

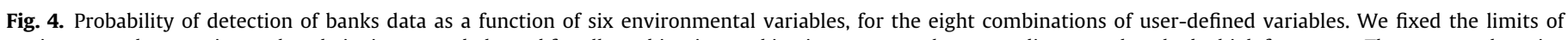

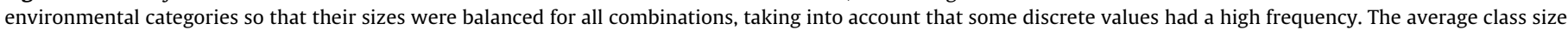
across combinations and classes was 228 (standard deviation =16). Note that the $x$-axis was log-transformed for the P-RR variable.

habitats (compare Figs. 3 and 4). They had a lower detection probability than drags on average, consistently with their low C-VA and high P-RR. However, detection probability was lower for banks data, even for comparable values of environmental variables.

Maps of detection probability showed similar spatial patterns among combinations (see Fig. 5A for an example). The lowest detection probabilities were located where hydrophones did not function and thus where the configuration variables were not favorable. Furthermore, detection probability was lower along the river banks (Fig. 5A). Comparing Fig. 5A and B showed that the lowest probabilities of detection were located where the current velocity exceeded $1.6 \mathrm{~ms}^{-1}$. Scatter plots among environmental variables (see an example in Supplementary file S2) indicated that the influence of environmental variables could be complicated by a high positive correlation between $\mathrm{C}-\mathrm{NH}$ and $\mathrm{C}$ VA and a negative correlation between P-Dp and P-RR, for both drags and banks data. For drags data, $\mathrm{C}-\mathrm{NH}$ was also negatively correlated with $\mathrm{P}-\mathrm{CV}$. For banks data, $\mathrm{P}-\mathrm{CV}$ and $\mathrm{P}-\mathrm{Dp}$ were positively related.

\subsection{Environmental effects on positioning error within combinations}

For detected tags, environmental variables had weaker relationships with positioning error than with detection probability (Fig. 6 and Fig. 7). Configuration variables were again the main driver of positioning error, which was reduced when C-NH was high $(>12$ for drags, $>13$ for banks, Fig. 6a and Fig. 7a) and C-VA was high 

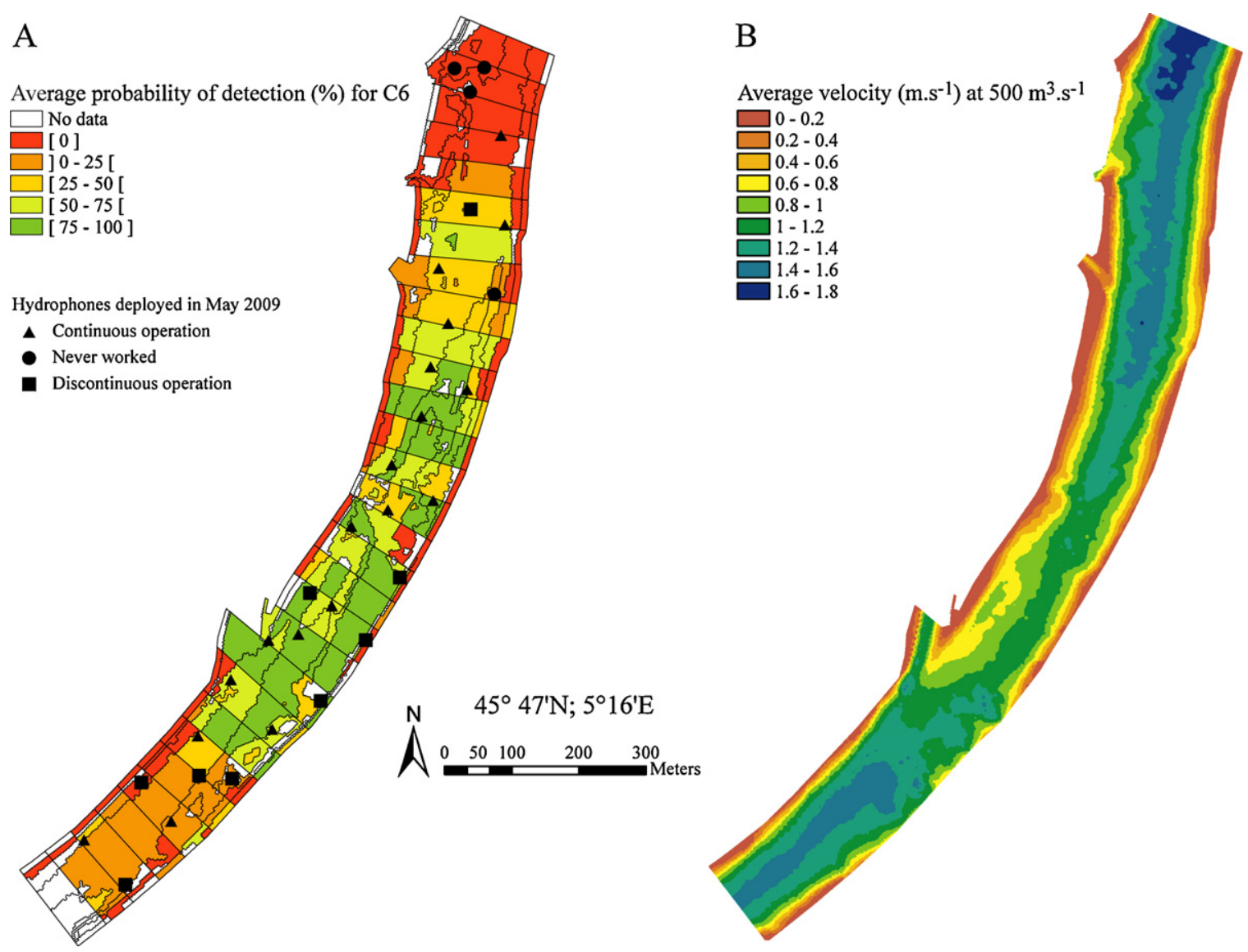

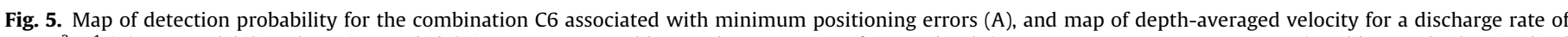

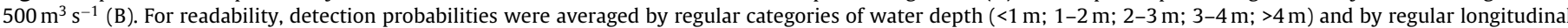

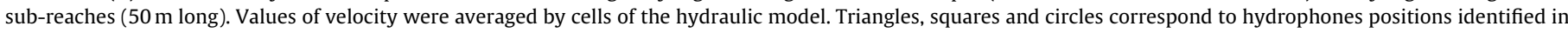
the matrix M2.

$\left(>156^{\circ}\right.$ for drags and banks, Fig. $6 \mathrm{~b}$ and Fig. 7b). However, these effects were not obvious for the two most accurate user-defined combinations for drags ( 66 and C5). High roughness (P-RR) noticeably reduced the error for banks data (Fig. 7f) and high velocities (P-CV) increased the error of drags data for the worse combinations only (Fig. 6c). Finally, indicators of reception quality were consistently related to the error, that could be increased (by a factor less than two) when I-VA decreased (Fig. 6i and Fig. 7i) and when I-MD and I-MAT increased (Fig. 6g, h and Fig. 7g, h). I-NR had no obvious relationship with the error (Fig. $6 \mathrm{j}$ and Fig. $7 \mathrm{j}$ ). Detected banks data had errors generally two times larger than drags data (Table 2). This was consistent with their C-VA and I-VA being two times lower and their P-RR being ten times larger (see the Supplementary file S3). Note that I-NR of detected tags were two times lower for banks, i.e. though noise did not explain error variations within drags and banks data, it could partly explain differences between the two data sets.

Maps of positioning errors of detected tags showed similar spatial patterns among combinations (see Fig. 8 for an example) and reflected that the environment affected positioning errors less than detection probability. The positioning errors were higher along river banks, and tended to be higher in areas where hydrophones did not function properly. Scatter plots among environmental variables (see an example in Supplementary file S2) indicated that their influence on positioning errors could be complicated by the same inter-correlations as those described for the probability of detection. In addition, they indicated strong correlations among the indicators of reception conditions (except I-NR) and the configuration variables for banks data.

\subsection{Differences in detection probability and positioning error between combinations}

The average probability of detection varied among user-defined combinations between $34.6 \%$ (combination C3) and $47.2 \%$ (C5) for drags data (Table 2) and between 8.3\% (C3) and 17.7\%(C5) for banks data (Table 2). It was higher when PT was PT-HTI and M was M2 (for drags and banks). The average positioning error varied more strongly between combinations: between $3.6 \mathrm{~m} \mathrm{(C6)} \mathrm{and} 10.7 \mathrm{~m}$ (C3) for drags data (Table 2) and between $7.7 \mathrm{~m}$ (C7) and $22.3 \mathrm{~m}$ (C4) for banks data (Table 2). It was primarily influenced by PT (i.e. it generally reduced two-fold when PT was PT-HTI), and secondarily reduced when M was M2 and SpS was 30 (for drags only). Environmental variables did not differ much between combinations, for both drags and banks (see the Supplementary file S3), and the most accurate combinations (C6 and C5) did not select particular environmental characteristics.

The sensitivity analysis detailing the effects of PT parameters showed that the probability of detection was very sensitive (i.e. could be modified by about $40 \%$ ) to a few software parameters influencing echo tracking (i.e. minimum and maximum number of echoes required for a series of echoes from one hydrophone, maximum gaps allowed in this series and maximum distance allowed between two echoes, Supplementary file S1). The average positioning error was mostly influenced (with modifications of about $10 \mathrm{~m}$ ) by an interpolation parameter (number of echoes used to smooth positions, Supplementary file S1). Different values of these parameters potentially explained differences observed between the PT-HTI and PT-JB settings. 

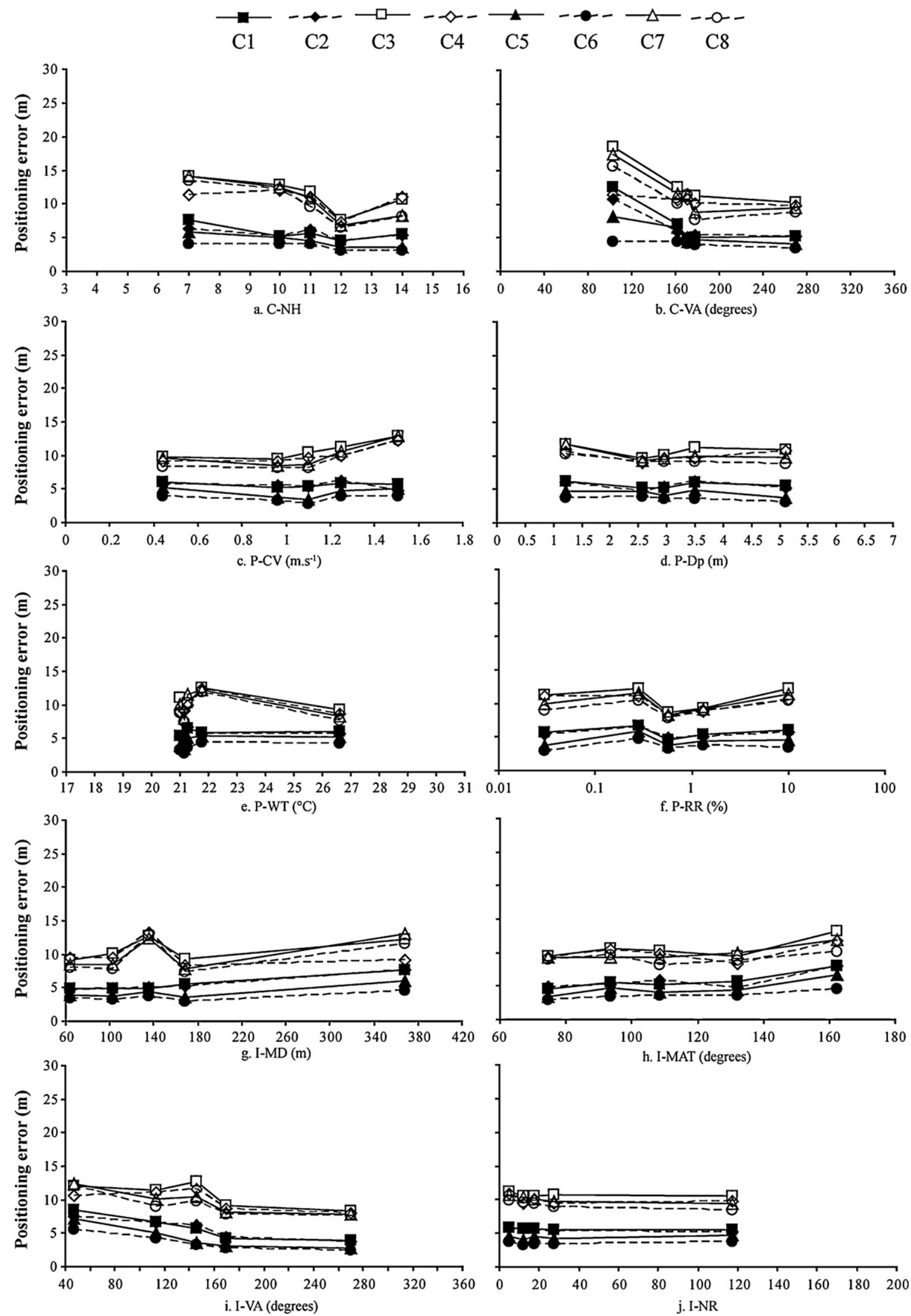

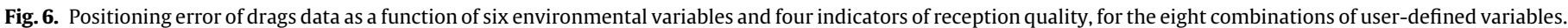

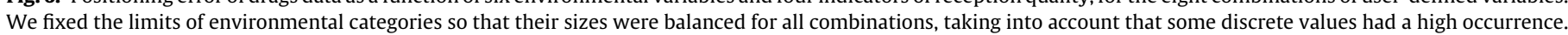
The average class size across combinations and classes was 985 (standard deviation $=504$ ). Note that the $x$-axis was log-transformed for the P-RR variable. 

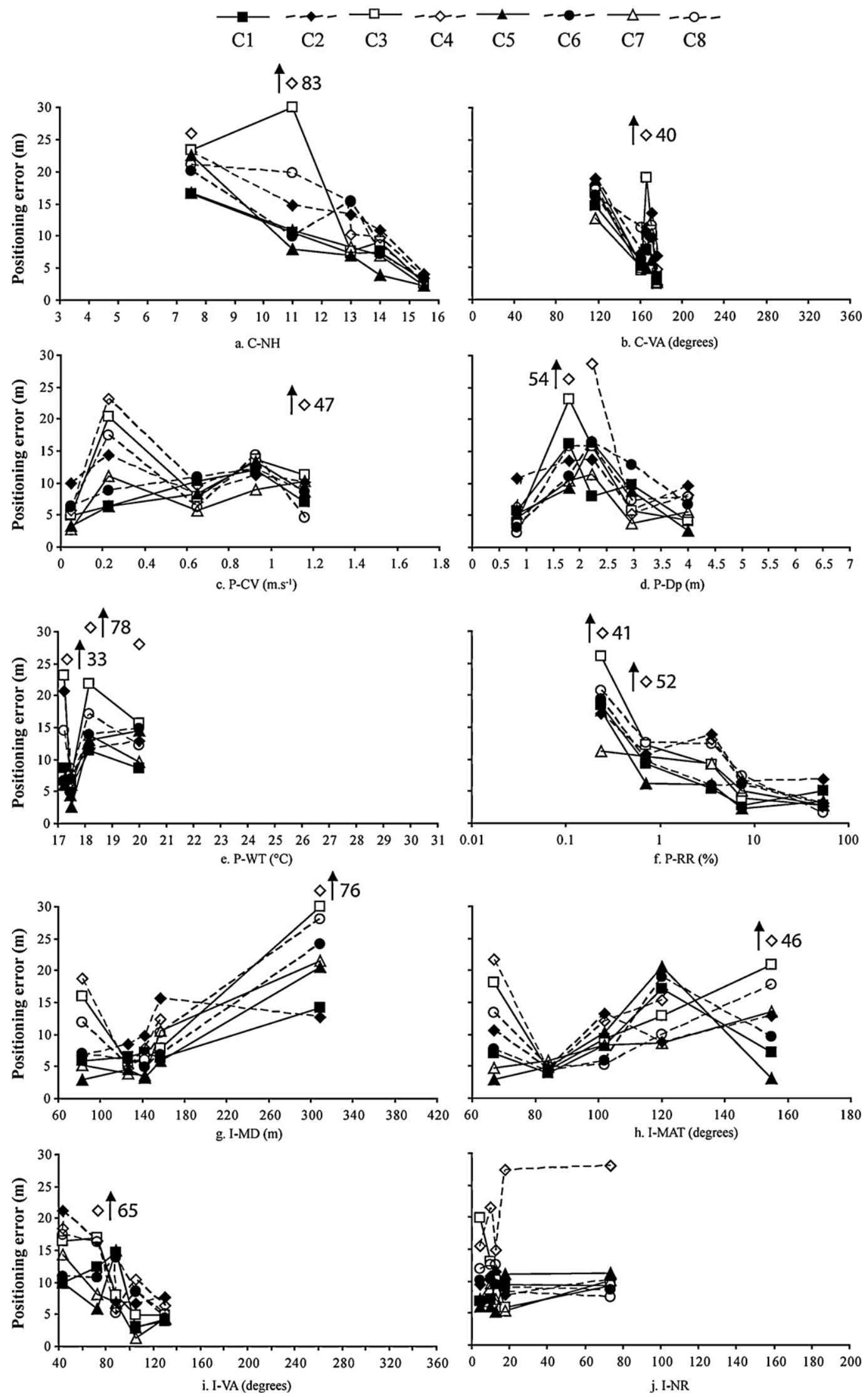

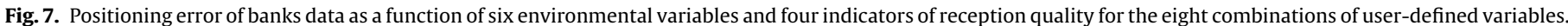

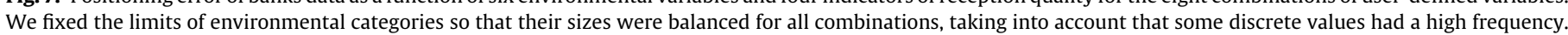

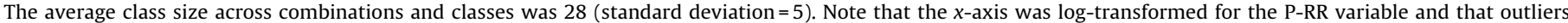
(positioning error $>30 \mathrm{~m}$ ) were indicated using arrows in each panel. 


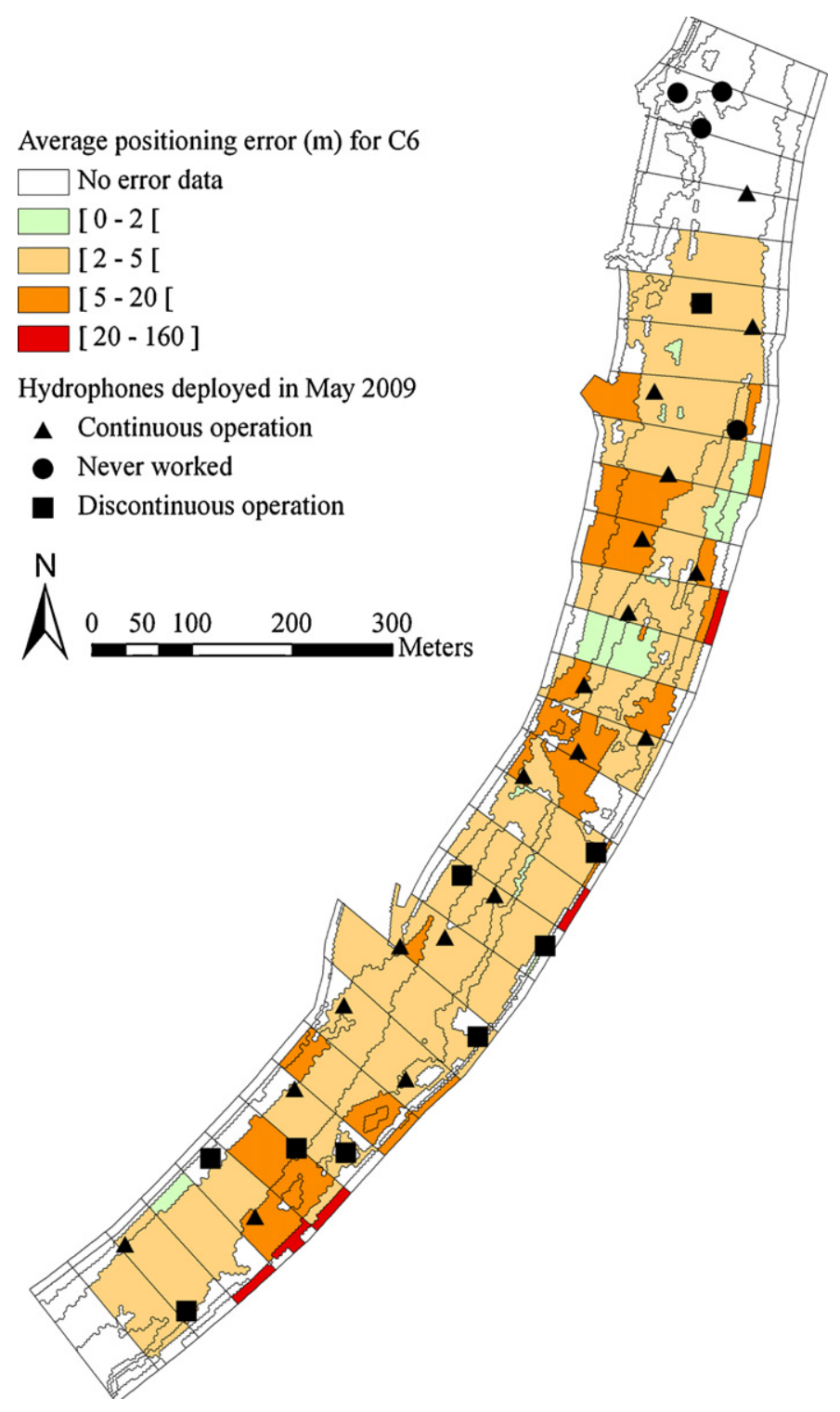

Fig. 8. Maps of positioning error for the combination C6. For readability, positioning errors were averaged by regular categories of water depth $(<1 \mathrm{~m} ; 1-2 \mathrm{~m} ; 2-3 \mathrm{~m}$; $3-4 \mathrm{~m} ;>4 \mathrm{~m}$ ) and by regular longitudinal sub-reaches ( $50 \mathrm{~m}$ long). Triangles, squares and circles correspond to hydrophones positions identified in the matrix M2.

\section{Discussion}

Our assessment test of the $\mathrm{HTI}^{\circledR}$ system in heterogeneous environmental conditions showed that the effects of intrinsic user-defined variables and environmental variables were largely independent. Environmental variables were the main variables affecting detection probability, principally the configuration of hydrophones around tags and secondarily relative roughness and velocity. For detected tags, user-defined variables (the post-treatment parameters and secondarily the knowledge of hydrophone positions) were the main determinants of positioning error. Configuration variables had only a secondary influence on the positioning error, especially along the banks.

In our study, the best user-defined combination provided an average detection probability of $44 \%$ in the channel ( $16 \%$ for banks) and an average positioning error of $3.6 \mathrm{~m}$ in the channel $(9.5 \mathrm{~m}$ for banks). Our installation was less accurate than a few others made in more homogeneous physical conditions and/or with higher hydrophone densities: e.g., a probability of detection of $75 \%$ in
Niezgoda et al. (2002) obtained with a CDMA (Code Division Multiple Access, Lotek Map_500 ${ }^{\mathrm{TM}}$ ) or positioning errors around $1 \mathrm{~m}$ in Semmens (2008) obtained with the same HTI system used in the present study. This was largely expected due to the nature of our experiment, whose originality was to test the system in harsh conditions for identifying the determinants of tag detection and positioning error and quantifying their effects.

Our study quantifies how configuration variables can dramatically influence detection probability, and to a lesser extent positioning errors, though the relative role of our two configuration variables was difficult to sort out due to inter-correlation. This effect of hydrophones configuration can partly explain differences in detection probability between previous studies. For example, the study of Niezgoda et al. (2002) obtained a high probability of detection with four hydrophones installed in a delta estuarine wetland with a density of one hydrophone for around $375 \mathrm{~m}^{2}$. In another study, Carol et al. (2007) reported a probability of detection of less than $10 \%$ with three hydrophones (Vemco radio-acoustic positioning system) installed in a Spanish reservoir with a density of one hydrophone for around $23,000 \mathrm{~m}^{2}$ (one third of the triangle surface formed by the listening trio). In our study, we had on average one hydrophone for about $7000 \mathrm{~m}^{2}$, and correspondingly intermediate detection probabilities. Other parameters such as transmitter power and frequency could also have contributed to differences among studies. For example, the lower frequency used by Niezgoda et al. (2002), i.e. $76 \mathrm{kHz}$, can also explain their higher detection probability.

The effect of hydrophone configuration on positioning error in our experiment was secondary compared to its effect on detection probability. Consistently, Carol et al. (2007) reported positioning errors of less than $1 \mathrm{~m}$ within the hydrophones array despite their low detection probability. Nevertheless, the influence of configuration (and in particular viewing angles) on positioning errors is consistent with previous results that reported higher errors outside the arrays of hydrophones (Juell and Westerberg, 1993; Kell et al., 1994; Ehrenberg and Steig, 2002; Niezgoda et al., 2002; Espinoza et al., 2011). In our study, both viewing angles and hydrophone densities were often low, largely explaining that our positioning errors could be higher than those obtained in some previous studies (e.g. Carol et al., 2007; Semmens, 2008).

The study of the effect of physical conditions at tag emissions is original to this study, and generally revealed weak effects on the probability of detection and the positioning error. However there was a negative influence of high relative roughness conditions. Higher velocities were associated with lower probabilities of detection for drags data, but this could be due to the negative correlation between velocity and the density of hydrophones (i.e. hydrophones did not work in high velocity areas). Similarly, higher detection probability in fast-flowing and deep conditions for banks data likely reflected a confounding effect: among points of the banks data, those with higher velocity and depth (the two variables being correlated) were closer to the main channel and were better detected. Similar confounding effects along the banks were reported by Melnychuk and Christensen (2009). Concerning the temperature, a weak effect of thermal conditions on detection probability was highlighted but was also likely confounded with spatial patterns. Indeed, the intermediate temperature category associated with high detection probability was different for drags and banks, and was situated in the middle of the reach for both data sets.

Therefore, it is very likely that physical variables affect the probability of detection and the positioning error only through indirect mechanisms, as in fast-flowing zones where high velocities may damage hydrophones or their connections. The clearer effect of the physical environment is that a lower probability of detection was observed along banks, as expected and reported in previous 
studies. This effect probably results from weak configurations and high levels of sound reflection in these shallow areas with high relative roughness (Cato and Bell, 1992; Juell and Westerberg, 1993; Trevorrow, 1998; Boswell et al., 2007), as also suggested by our indirect indicators of reception quality.

Experience for tuning PT parameter values had, overall, less influence on the probability of detection than environmental factors in our study. However, our sensitivity analysis indicated that a particular attention should be given in future applications to the parameters influencing echo tracking, since these can alter the probability of detection. The lower positioning error obtained with the expert parameter settings was partly due to an interpolation parameter (number of echoes used to smooth tag position tracks) whose tuning also requires attention. These results suggest that a full understanding of the parameter calibration process is necessary to get the best capabilities from the system, especially when the possibilities of parameter values are numerous and closely dependent on the physical characteristics of the study site.

At the core of our study, the knowledge of the positions of hydrophones (matrix $\mathrm{M}$ ) and speed of sound ( $\mathrm{SpS}$ ) had much weaker influence on the positioning error than PT parameters. This is surprising when considering their predominant role emphasized in the literature (Juell and Westerberg, 1993; Kell et al., 1994; Cote et al., 1998; Wahlberg et al., 2001). Still, M and SpS could affect positioning errors by a meter or more, and they would probably have played a more important role in better configuration conditions. It is also possible that our two $\mathrm{M}$ matrices were both inaccurate on the experimental days, but the hydraulic conditions of the site prevented us from checking this aspect. Using the coordinates of the hydrophones measured at the end of the experiment improved our results, and this procedure is recommended for future experiments in fast-flowing rivers. Indeed, it is likely that the hydrophones rapidly moved after deployment and then stabilized on the bed.

The main practical lesson of our methodological study is that fixed acoustic telemetry systems can be used efficiently in fast-flowing rivers with high stresses and velocities, where they provided a reasonable detection probability and positioning error, despite a relatively low density of hydrophones installed within a $234,600 \mathrm{~m}^{2}$ area. The probability of detection and the positioning error obtained here can be certainly improved with higher hydrophone densities and/or reduced study areas. However, it would be satisfactory for a number of ecological studies for which a higher quantity of accurate positions is not needed. As an example, for studies on the relationships between the physical habitat and the detailed movement of many fish individuals of several fish species in our reach, a fixed telemetry system is appropriate and a positioning error of $3-5 \mathrm{~m}$ is satisfactory considering the uncertainty of the hydraulic model. The main limit of fixed telemetry systems in large rivers seems to be the difficulty of deployment, illustrated by the length of weighted cables that were needed in the Rhone River $(16 \mathrm{~km})$ and the number of hydrophones that were temporarily disconnected (up to 11 out of 32 ), mostly due to scouring around blocks or accidents with trees in fast-flowing areas.

Because our results quantify the probability of detection and the positioning error for a variety of intrinsic and environmental combinations, we hope that they provide useful guidelines for optimizing future installations. Recommendations for improving detection and errors certainly depend on the objectives of the telemetry study (Kell et al., 1994). Studies for which detection probability is important, for example when tracking animals with frequent and large movements, should pay a particular attention to local hydrophone densities and viewing angles. If banks are of particular importance in such studies, our results can be used to quantify how the hydrophone density and angles should be increased near the banks to obtain a satisfactory probability of detection. For studies for which positioning error is more important (e.g. for some studies on species interaction), our results suggest paying particular attention to system parameter values. Evaluation tests of the system would be particularly useful in such conditions and can serve to optimize intrinsic parameter values. In all cases, high roughness zones should be better covered. Zones with extreme velocities or temperature fluctuations should not be problematic for the probability of detection and the positioning error, but should be avoided if a risk of damaging the hydrophones is identified. We recommend paying particular attention to the hydrophone mounting and installation method in such conditions and to choose an aerial deployment of cables when possible.

\section{Acknowledgements}

The authors thank the Water Agency Rhône Méditerranée \& Corse, Electricity of France (EDF), the European Union / FEDER, the General Direction of Irstea and the Aquitaine region for their financial support, the Nuclear Power Plant of Bugey (EDF) for their collaboration, Eric McNeil, Samuel Johnston, Patrick Nealson, Dave Ouellette, Pascal Roger and Raphael Mons for their help during material installation and software calibration. Special thanks to Yann Le Coarer for his help with tachometer measures and to Alizés plongée $^{\circledR}$ for its involvement in the diving operation. Finally, we thank the anonymous reviewers, André St Hilaire and Lise Vaudor for their comments and assistance.

\section{Appendix A. Supplementary data}

Supplementary data associated with this article can be found, in the online version, at doi:10.1016/j.fishres.2012.02.008.

\section{References}

Baras, E., Lagardère, J.P., 1995. Fish telemetry in aquaculture: review and perspectives. Aquacult. Int. 3, 77-102.

Boswell, K.M., Wilson, M.P., Wilson, C.A., 2007. Hydroacoustics as a tool for assessing fish biomass and size distribution associated with discrete shallow water estuarine habitats in Louisiana. Estuaries Coasts 30, 607-617.

Capra, H., McNeil, E., Bouillon, M.C., Pella, H., Alfaro, C., 2011. Relevance of 2D hydraulic model to address fish behaviour in large rivers. La Houille Blanche 6, 28-33.

Capra, H., Pella, H., Oriol, E., 2008. Records from the water temperature of the Rhône river in the summer of 2008. Electricity of France - Cemagref Report, p. 37.

Carol, J., Zamora, L., García-Berthou, E., 2007. Preliminary telemetry data on the movement patterns and habitat use of European catfish (Silurus glanis) in a reservoir of the River Ebro, Spain. Ecol. Freshwat. Fish 16, 450-456.

Cato, D.H., Bell, M.J., 1992. Ultrasonic ambient noise in Australian shallow waters at frequencies up to $200 \mathrm{kHz}$. DSTO Mat. Res. Lab., Tech. Rep. MRL-TR-91-23, February, p. 25.

Clements, S., Jepsen, D., Karnowski, M. Schreck, C.B. 2005. Optimization of an acoustic telemetry array for detecting transmitter-implanted fish. N. Am. J. Fish. Manage. 25, 429-436.

Cooke, S.J., Bunt, C.M., Schreer, J.F., 2004. Understanding fish behavior, distribution, and survival in thermal effluents using fixed telemetry arrays: a case study of smallmouth bass in a discharge canal during winter. Environ. Manage. 33 140-150.

Cooke, S.J., Niezgoda, G.H., Hanson, K., Suski, C.D., Phelan, F.J.S., Tinline, R., Philipp, D.P., 2005. Use of CDMA acoustic telemetry to document 3-D positions of fish Relevance to the design and monitoring of aquatic protected areas. Mar. Technol Soc. J. 39, 17-27.

Cote, D., Scruton, D.A., Niezgoda, G.H., Mckinley, R.S., Rowsell, D.F., Lindstrom, R.T Ollerhead, L.M.N., Whitt, C.J., 1998. A coded acoustic telemetry system for high precision monitoring of fish location and movement: application to the study of nearshore nursery habitat of juvenile Atlantic cod (Gadus morhua). Mar. Technol. Soc. J. 32, 54-62.

Craven, S.W., Peterson, J.T., Freeman, M.C., Kwak, T.J., Irwin, E., 2010. Modeling the relations between flow regime components, species traits, and spawning success of fishes in warmwater streams. Environ. Manage. 46, 181-194.

Del Grosso, V.A., Mader, C.W., 1972. Speed of sound in pure water. J. Acoust. Soc. Am. 52, 1442-1446.

Ehrenberg, J.E., Steig, T.W., 2002. A method for estimating the position accuracy of acoustic fish tags. ICES J. Mar. Sci. 59, 140-149.

Ehrenberg, J.E., Steig, T.W., 2003. Improved techniques for studying the tempora and spatial behavior of fish in a fixed location. ICES J. Mar. Sci. 60, 700-706. 
Espinoza, M., Farrugia, T.J., Webber, D.M., Smith, F., Lowe, C.G., 2011. Testing a new acoustic telemetry technique to quantify long-term, fine-scale movements of aquatic animals. Fish. Res. 108, 364-371.

Fritsch, F.N., Carlson, R.E., 1980. Monotone piecewise cubic interpolation. SIAM J. Numer. Anal. 17, 238-246.

Geeraerts, C., Ovidio, M., Verbiest, H., Buysse, D., Coeck, J., Belpaire, C., Philippart, J.C., 2007. Mobility of individual roach Rutilus rutilus (L.) in three weir-fragmented Belgian rivers. Hydrobiologia 582, 143-153.

Heupel, M.R., Semmens, J.M., Hobday, A.J., 2006. Automated acoustic tracking of aquatic animals: scales, design and deployment of listening station arrays. Mar. Freshw. Res. 57, 1-13.

Juell, J.E., Westerberg, H., 1993. An ultrasonic telemetric system for automatic positioning of individual fish used to track Atlantic salmon (Salmo salar L.) in a sea cage. Aquacult. Eng. 12, 1-18.

Kell, L.T., Russell, I.C., Challis, M.J., 1994. Development of a high resolution tracking system for monitoring the movement of migratory fish past obstructions. In: Proceedings of the IFM 25th Annual Study Course, pp. 269-288.

Lucas, M.C., Batley, E., 1996. Seasonal movements and behaviour of adult barbel Barbus barbus, a riverine cyprinid fish: implications for river management. J. Appl. Ecol. 33, 1345-1358.

Lukšiené, D., Sandström, O., Lounasheimo, L., Andersson, J., 2000. The effects of thermal effluent exposure on the gametogenesis of female fish. J. Fish Biol. 56, 37-50.

Lyons, J., Lucas, M.C., 2002. The combined use of acoustic tracking and echosounding to investigate the movement and distribution of common bream (Abramis brama) in the River Trent, England. Hydrobiologia 483, 265-273.

Melnychuk, M.C., Christensen, V., 2009. Methods for estimating detection efficiency and tracking acoustic tags with mobile transect surveys. J. Fish Biol. 75, 1773-1794.

Meyer, L., Hinrichs, D., 2000. Microhabitat preferences and movements of the weatherfish, Misgurnus fossilis, in a drainage channel. Environ. Biol. Fish. 58, 297-306.

Minns, C.K., Kelso, J.R.M., Randall, R.G., 1996. Detecting the response of fish to habitat alterations in freshwater ecosystems. Can. J. Fish. Aquat. Sci. 53, 403-414.

Niezgoda, G.H., Benfield, M., Sisak, M., Anson, P., 2002. Tracking acoustic transmitters by code division multiple access (CDMA)-based telemetry. Hydrobiologia 483 , 275-286.

O‘dor, R.K., Andrade, Y., Webber, D.M., Sauer, W.H.H., Roberts, M.J., Smale, M.J., Voegeli, F.M., 1998. Applications and performance of radio-acoustic positioning and telemetry (RAPT) systems. Hydrobiologia 372, 1-8.

Olden, J.D., Naiman, R.J., 2010. Incorporating thermal regimes into environmental flows assessments: modifying dam operations to restore freshwater ecosystem integrity. Freshwater Biol. 55, 86-107.

Olivier, J.M., Carrel, G., Lamouroux, N., Dole-Olivier, M.J., Malard, F., Bravard, J.P., Amoros, C., 2009. The Rhône River Basin. In: Tockner, K., Robinson, C.T. Uehlinger, U. (Eds.), Rivers of Europe. Academic Press, London, pp. 247-295.

Ovidio, M., Baras, E., Goffaux, D., Birtles, C., Philippart, J.C., 1998. Environmenta unpredictability rules the autumn migration of brown trout (Salmo trutta L.) in the Belgian Ardennes. Hydrobiologia 372, 263-274.
Ovidio, M., Capra, H., Philippart, J.C., 2007. Field protocol for assessing small obstacles to migration of brown trout Salmo trutta, and European grayling Thymallus thymallus: a contribution to the management of free movement in rivers. Fisheries Manage. Ecol. 14, 41-50.

Ovidio, M., Capra, H., Philippart, J.C., 2008. Regulated discharge produces substantial demographic changes on four typical fish species of a small salmonid stream. Hydrobiologia 609, 59-70.

Ovidio, M., Philippart, J.C., 2008. Movement patterns and spawning activity of individual nase Chondrostoma nasus (L.) in flow-regulated and weir-fragmented rivers. J. Appl. Ichthyol. 24, 256-262.

Pella, H., Capra, H., Foulard, S., 2007. Développement d'un MNT du haut Rhône à partir de relevés bathymétriques réalisés avec un sondeur multi-faisceaux. Rev. Franç. Photogrammétr. Télédétection 186, 81-86.

Poff, N.L., Zimmerman, J.K.H., 2010. Ecological responses to altered flow regimes: a literature review to inform the science and management of environmental flows. Freshwater Biol. 55, 194-205.

$\mathrm{R}$ Development Core Team. 2010. R: A language and environment for statistical computing. R Foundation for Statistical Computing, Vienna, Austria. ISBN 3900051-07-0.

Roger, M.C., Capra, C., Roger, P., Le Goff, G., 2010. Hydrobiological monitoring of the Bugey site in 2009. Electricity of France - Cemagref Rep., p. 69.

Semmens, B.X., 2008. Acoustically derived fine-scale behaviors of juvenile Chinook salmon (Oncorhynchus tshawytscha) associated with intertidal benthic habitats in an estuary. Can. J. Fish. Aquat. Sci. 65, 2053-2062.

Simpfendorfer, C.A., Heupel, M.R., Hueter, R.E., 2002. Estimation of short-term centers of activity from an array of omnidirectional hydrophones and its use in studying animal movements. Can. J. Fish. Aquat. Sci. 59, 23-32.

Smith, G.W., Urquhart, G.G., Maclennan, D.N., Sarno, B., 1998. A comparison of theoretical estimates of the errors associated with ultrasonic tracking using a fixed hydrophone array and field measurements. Hydrobiologia 372, 9-17.

Takac, F., Walford, J., 2006. Leica system 1200 - High performance GNSS technology for RTK applications. In: Proceedings of Conference of Institute of Navigation GNSS - 19th International Technical Meeting of the Satellite Division, 26-29 September 2006, Fort Worth, TX, pp. 217-225.

Trevorrow, M.V., 1998. Boundary scattering limitations to fish detection in shallow waters. Fish. Res. 35, 127-135.

Vehanen, T., Bjerke, P.L., Heggenes, J., Huusko, A., Maki-Petays, A., 2000. Effect of fluctuating flow and temperature on cover type selection and behaviour by juvenile brown trout in artificial flumes. J. Fish Biol. 56, 923-937.

Voegeli, F.A., Pincock, D.G., 1996. Overview of underwater acoustics as it applies to telemetry. In: Baras, E., Philippart, J.C. (Eds.), Proceedings of the First Conference and Workshop on Fish Telemetry in Europe (no. 4-4-0095). University of Liège Belgium, pp. 23-30.

Wahlberg, M., Mohl, B., Madsen, P.T., 2001. Estimating source position accuracy of a large-aperture hydrophone array for bioacoustics. J. Acoust. Soc. Am. 109, 397-406. 